\title{
Catecholamine Metabolite
}

National Cancer Institute

\section{Source}

National Cancer Institute. Catecholamine Metabolite. NCI Thesaurus. Code C129882.

Molecules created during the catabolism of catecholamine hormones. Increased concentrations of these metabolic products in plasma and urine may indicate the presence of hormone-producing pheochromocytomas or paragang liomas. 